\title{
Evaluation of pool water quality of trout farms by fuzzy logic: monitoring of pool water quality for trout farms
}

\author{
A. Yalcuk $\cdot$ S. Postalcioglu
}

Received: 3 February 2013/Revised: 16 December 2013/ Accepted: 5 March 2014/Published online: 19 March 2014

(C) Islamic Azad University (IAU) 2014

\begin{abstract}
Pool water must have a certain quality parameters for the vital processes of trout. For this purpose, monitoring of a pool water quality of trout farms is realized using fuzzy logic with graphical user interface (GUI). Pool water qualities of four trout farms with different sources were investigated in terms of chemical oxygen demand, ammonium nitrogen, $\mathrm{pH}$ and electrical conductivity parameters during 270 days of study period between August 2011 and April 2012. The resulting data set created a $21 \times 32$-sized matrix for all parameters. Comparison between input and output waters of pools is made with SPSS (PASW 18) software for parameter changes in the pools. It would be too difficult for the observer researcher to interpret this set, a computer program was developed with fuzzy logic system, the decision-making tool, to graphically present the Turkish Water Pollution Control by laws state in pool water quality. Fuzzy logic was used in the evaluation of these data and notification of the critical states which exceeded the limiting values. The classification of the product of the quality characteristics is performed by human experts due to the absence of measuring devices. The program is developed to graphically present the conditions regarding pool water quality with GUI. Fuzzy logic results are presented on the monitors. The results enable even those people with inadequate
\end{abstract}

\footnotetext{
A. Yalcuk $(\square)$

Faculty of Engineering and Architecture, Environmental Engineering, Abant Izzet Baysal University, Golkoy Campus, Bolu, Turkey

e-mail: ayalcuk@gmail.com

S. Postalcioglu

Faculty of Engineering and Architecture, Electrical Electronics Engineering, Abant Izzet Baysal University, Golkoy Campus, Bolu, Turkey
}

knowledge about the subject to comment on pool water quality of farms. This software increases awareness of the water quality.

Keywords Environmental monitoring · Fuzzy logic . Graphical user interface · Trout farm water quality

\section{Introduction}

With population growth, reduction in natural stocks and higher education level, the increasing consciousness that fish is the healthiest source of protein further increases the importance of aquaculture. Thus, the number of entrepreneurs in culture fishery increases, which is expected to continue in the future. The origin and quality of water source to be used in trout production are required to be high. The water sources used in trout production include spring waters, stream and river waters, lake and pond waters lastly underground waters (Aydın 2008).

The ideal condition in trout production is to provide regularly the same quality water at all time to fishes in growing environment. At the same time, the close relation between water quantity and quality should not be disregarded. In this respect, it should be kept in mind that sudden changes in water quantity could adversely or positively affect the present quality parameters of water. The limits values of various parameters that should be examined regarding water quality in trout production are given in Table 1 (Lindhorst-Emme 1990).

More attention should be given to the quality of water to be used in incubation house where fertilized eggs are incubated. For the needs of fertilized trout eggs and larvae, as much as clean and unpolluted water should be used. From this regard, it would be useful to filter water before 
Table 1 Limit values of various water parameters in trout production (Lindhorst-Emme 1990)

\begin{tabular}{ll}
\hline Parameter & Limit value \\
\hline Temperature & Until $20{ }^{\circ} \mathrm{C}$ \\
Oxygen & Over $7 \mathrm{mg} / \mathrm{L}$ \\
$\mathrm{pH}$ & $5.5-8.5$ \\
Acid binding capacity $(\mathrm{SBV})$ & Over $1.5 \mathrm{Vol} . / \mathrm{m}^{3}$ \\
Ammonium nitrogen $\left(\mathrm{NH}_{4}-\mathrm{N}\right)$ & Until $1.0 \mathrm{mg} / \mathrm{L}$ \\
Total Fe & Until $0.5 \mathrm{mg} / \mathrm{L}$ \\
Nitrite $\left(\mathrm{NO}_{2}-\mathrm{N}\right)$ & Until $0.2 \mathrm{mg} / \mathrm{L}$ \\
Nitrate $\left(\mathrm{NO}_{3}-\mathrm{N}\right)$ & Until $10 \mathrm{mg} / \mathrm{L}$ \\
Potassium permanganate consumption $\left(\mathrm{KMnO}_{4}\right)$ & Until $40 \mathrm{mg} / \mathrm{L}$ \\
Chemical oxygen demand $(\mathrm{COD})$ & Until $40 \mathrm{mg} / \mathrm{L}$ \\
Biological oxygen demand (BOD) & Until $15 \mathrm{mg} / \mathrm{L}$ \\
Oxygen consumption $\left(\mathrm{O}_{2}\right)$ & Until $6 \mathrm{mg} / \mathrm{L}$ \\
Free $\mathrm{CO}_{2}$ (for larvae) & Under $15 \mathrm{ppm}$ \\
Free $\mathrm{CO}_{2}$ (for edible fishes) & Under $30 \mathrm{ppm}$ \\
\hline
\end{tabular}

Table 2 Properties of water used in incubation house (LindhorstEmme 1990)

\begin{tabular}{llclc}
\hline $\begin{array}{l}\text { Water } \\
\text { temperature } \\
{ }^{\circ} \mathrm{C}\end{array}$ & Oxygen & $\mathrm{pH}$ & $\begin{array}{l}\text { Acid } \\
\text { binding } \\
\text { capacity }\end{array}$ & Free $\mathrm{CO}_{2}$ \\
\hline $8-10$ & $\begin{array}{c}9-11 \mathrm{mg} / \mathrm{L} \\
\text { saturation level } \\
80-100 \%\end{array}$ & $6.5-7.5$ & $\begin{array}{c}2-5 \mathrm{ml} / \mathrm{L} \\
\text { or higher }\end{array}$ & $\begin{array}{c}\text { Under } \\
20 \mathrm{ppm}\end{array}$ \\
& & & & \\
\hline
\end{tabular}

giving to the incubation house. The size of incubation house depends on the amount of fertilized eggs and the type of incubation tools in use. The water need of a middlesized incubation house is around $3-5 \mathrm{~L}$ per second. The values regarding the water used in incubation house are presented in Table 2 (Lindhorst-Emme 1990).

Aquaculture made in farmers or cages established in land releases considerable amount of waste in water environment. Feeds account for the most important nutrient input in aquaculture. More than $90 \%$ of feeds given to fish in aquaculture are passed to water and then to sediments as waste nutrient matters and fish excretion (Tsutsumi et al. 1991).

Some nutrient matters in discharge of fish production pools are absorbed by soil, and an important part is suitable for organic matter production. Feed wastes are minimized in well-organized farms (Pillay 1992). Fish excretion and feed wastes discharged by fish farms into river and lakes are important pollution factors and their effects and size are unknown.

Many issues need to be taken into consideration simultaneously in aquaculturing including the pollution of water resources, familiarization of exotic species in wilderness, modifications in the hydrological regime and the struggle among the needs of the end product users; all these issues were reported to constitute different aspects of the environmental impact that aquaculturing created (Midlen and Redding 1998; Read et al. 2001). The most frequently encountered complaint was reported as the pollution of water resources by pond effluents by Boyd (2003) and the official attraction of most nations was focused on issues regarding this common complaint. An enhancement of the effluents with nutrients and solids would be observed in flow-through aquaculturing systems that discharged their water out of a series of raceways and tanks. The untreated discharge of such effluents was reported to adversely affect the quality of the water into which the effluent was mixed (Forenshell 2001; Miller and Semmens 2002; Schulz et al. 2003). Waste management and effective feed management were the followed routes in recent years in order to reduce waste in the aquaculture industry and to implement environmentally friendly and sustainable fish farming practices. The potential adverse effects of aquaculturing were also made to be minimized by the governments through the implementation of environmental safeguards to regulate, control and monitor the farming processes (Midlen and Redding 1998; Forenshell 2001; Henderson and Davies 2000; Read et al. 2001; Bergheim and Brinker 2003). The necessary environmental safeguard regulations would only be structured by the decision makers, and the fish farmers would adopt and develop their own waste management systems through the provision of the necessary information and the database on the environmental impact of aquaculturing including the characterization of fish farm effluents and the quantification of its environmental impact (Pulatsu et al. 2004). The effectiveness of water quality indices (WQIs) in the specific assessment of trout culture impacts on a stream water quality is checked by Koçer and Sevgili (2014).

The analysis results provide an important data set in terms of water quality of trout farm. The investigation of this data set and reaching a decision presents both expert and time requirements. Fuzzy logic is used to eliminate these requirements.

Fuzzy logic is a new approach and intended to emulate human reasoning using calculations and operations with fuzzy groups and linguistic variables. Fuzzy logic is used in target tracking, pattern recognition, robotics, controller design, chemical engineering, vehicular technology, decision making, civil engineering, etc. In many chemical engineering systems, the classification of product of quality characteristics is performed by human experts due to the absence of measuring devices (Emami 2010). Wireless monitoring is studied for fish farm by Lopez et al. (2009). Fuzzy inference system is used for the immediate water quality assessment in the paper which is done by CarbajalHernández et al. (2012). A fuzzy-based model is studied 
for the evaluation of source water protection by Islam et al. (2013). A probabilistic fuzzy hybrid model to assess river water quality is proposed by Ocampo-Duque et al. (2013). The assessment of local sustainability using fuzzy logic is studied by Canavese et al. (2014).

Fuzzy logic, which has a wide usage area as mentioned above, is used in this study. Pool water qualities of four different trout farms in Bolu region are evaluated by fuzzy logic, which is a decision-making tool. The program is developed to graphically present the conditions regarding pool water quality without requiring expert opinion with the graphical user interface (GUI). GUI increases the awareness of the water quality. Graphical results could enable even those people who have insufficient knowledge about the subject to make comment about water quality. Thus, water and trout qualities directly increase. GUI increases the awareness of the pool water quality.

In this study, the inlet and outlet water of two trout farms that were situated on the 4th and the 20th $\mathrm{km}$ of the Abant Rivulet, third one is village of Civril and fourth one is village of Çayır in Bolu (Turkey), were investigated in a 9-month period between August 2011 and April 2012 in terms of their physicochemical parameters, and the results were evaluated in terms of the environmental impact that they generated.

\section{Materials and methods}

Winter conditions are severe in the study area. During 270 days of observation between August 2011 and April 2012, sampling from pools differed by weather conditions, and samples were taken once a week when roads were closed due to severe weather conditions and twice in normal times. Average rainfall is shown in Table 3.

Table 3 Mean rainfall amount $\left(\mathrm{kg} / \mathrm{m}^{3}\right)$ from SMS

\begin{tabular}{lrr}
\hline Months & 2011 & 2012 \\
\hline January & 31.6 & 64.2 \\
February & 14.2 & 85.7 \\
March & 60.5 & 82.6 \\
April & 84.5 & 38.3 \\
May & 67.6 & \\
June & 73.0 & \\
July & 14.2 & \\
August & 7.2 & \\
September & 14.1 & \\
October & 62.8 & \\
November & 5.2 & \\
December & 52.1 & \\
\hline
\end{tabular}

Samples were taken from inlet and outlet waters of pools between 09:00 and 10:00 o'clock in morning and some parameters were examined. Samples were put in $500-\mathrm{mL}$ polyethylene containers and analyzed in the same day, and the samples not analyzed were acidified and stored at $4{ }^{\circ} \mathrm{C}$ and then analyzed in $48 \mathrm{~h}$ at the latest. The analyses were conducted as stated in the standard methods (APHA 2005), chemical oxygen demand (COD) and ammonium nitrogen $\left(\mathrm{NH}_{4}-\mathrm{N}\right)$ were determined spectrophotometrically using Merck Pharo-100, and pH and electrical conductivity (EC) were determined using WTW multi-function.

\section{Monitoring of pool water quality}

Data obtained over 270 days were recorded in matrix form, yielding a $21 \times 32$-sized data set. Fuzzy logic was used to evaluate this data set and identify critical states which exceed the limiting values. There are three steps in the calculation of the output of the FLC: fuzzification, inference and defuzzification (Garido et al. 1997).

Fuzzification is the process of transforming input information taken from the system into symbolic data which are verbal qualifiers.

When $U_{i}^{*}$ signifies the set of all possible fuzzy sets to be defined in $U_{i}$ given $u_{i} \in U_{i}$, fuzzification converts $U_{i}$ to a fuzzy set shown by $\widehat{A}_{i}^{f u z}$ on the universe of discourse $U_{i}$. This transformation is produced by the fuzzification operator $F$, which is shown as $F: U_{i} \rightarrow U_{i}^{*}$. Here, $F\left(u_{i}\right)=\widehat{A}_{i}^{f u z}$ (Passino and Yurkovich 1997).

During the fuzzification, fuzzy inference and defuzzification processes performed within the controlled system, the required membership function and rule table information are brought into use. The decision-making unit processes fuzzy notions and determines the necessary control by making inference. The methods used for fuzzy inference are Max-Dot, Min-Max, Tsukamoto and Takagi-Sugeno. Min-max method was used for fuzzy inference in this study. A fuzzy cluster is obtained from the decision-making unit. This result has to be converted into numeric value to be used in the system again. This process is called defuzzification. The most used methods are maximum membership method, center of gravity method, mean weight method and mean-max membership method. Center of gravity method was used as the defuzzification method in the study. Center of gravity is the most commonly used defuzzification method. $\mu$ is the membership function of the cluster. The acquisition steps of $z^{*}$ resulting from the defuzzification method are given in Fig. 1 (Elmas 2003).

The structure of fuzzy logic is shown in Fig. 2. Knowledge base consists of database and rule base. Rule base determines control purposes and control strategy. The process was carried out using Matlab R2009b software. 


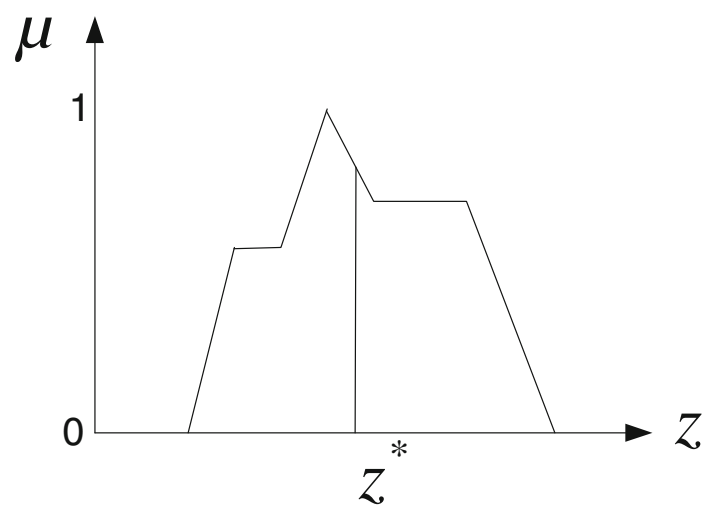

Fig. 1 Acquisition of $z^{*}$ value

In this section, the expert evaluation is transferred to programming and fuzzy logic was applied. A program was developed that would allow even people with inadequate knowledge about the subject to be able to interpret the situation using a simple graphical display. Data were evaluated as either instantaneous or massive data sets, and a conclusion was reached about the water quality. The general structure of the study is given in Fig. 3 .

The Matlab/Simulink program used in the study is given in Fig. 4. Fuzzy logic outputs were sent to an S-function structure. An $S$-function is a computer language description of a Simulink block written in MATLAB ${ }^{\circledR}, \mathrm{C}, \mathrm{C}++$, or Fortran. S-functions (system-functions) provide a powerful mechanism for extending the capabilities of the Simulink ${ }^{\circledR}$ environment (Mathworks 2012).

Figure 5 presents the structure of fuzzy logic. Input and output values of the pool indicate the inputs of fuzzy logic structure, while the input is the parameter change obtained for each pool.

Figure 6(a-d) represents the fuzzy logic layers designed for $\mathrm{COD}, \mathrm{EC}, \mathrm{NH}_{4}-\mathrm{N}$ and $\mathrm{pH}$ parameters. Logic inputs were named input and outputs and were used for input and output parameters of the trout pools. The result, which gave information about the parameter changes in the pools, was the output of fuzzy logic.

GUI been used to make the results more clear about the water quality. When fuzzy logic starts to run, GUI window is opened and the status of the parameters could be monitored easily. GUI is a tool for layout and programming. GUI is used for the fault diagnosis of DC motor by Postalcioglu Ozgen 2009. A GUI uses graphics and text inputs to make using Matlab much more user-friendly for people who are unfamiliar with it (Stephens 2007).

Once the GUI was physically designed as shown in Fig. 7, a code was attached to each component to complete the process. The saving process produced two files; pool.fig and pool.m. The $\mathrm{m}$ file contained as many subfunctions as there were components in the GUI layout. The $\mathrm{m}$ file and the figure file are shown in Fig. 7.

As shown in Fig. 7, push button, text boxes and axes were used. Push button executes some code when clicked. There were two types of text boxes, a static text box and an edit text box. To group all the controls together, a panel could be inserted around them using the panel button. The user can select the static text and insert a static text box into the GUI.

\section{Statistical analysis}

The independent sample $t$ test was performed in order to evaluate the effect of the tank water in farms A, B, C and D. The removal efficiencies were analyzed using the independent sample $t$ test with a significance threshold of 0.05 throughout the 270-day period of monitoring for the environmental quality parameters. SPSS (PASW 18) software was used to conduct the statistical analysis. The results are presented as the following form: $(t, d f, p)$ where $t=t$ value, $d f=$ degrees of freedom, and $p>0.05$ in the relevant parts of the "Results and discussion" section.

Fig. 2 Structure of fuzzy logic

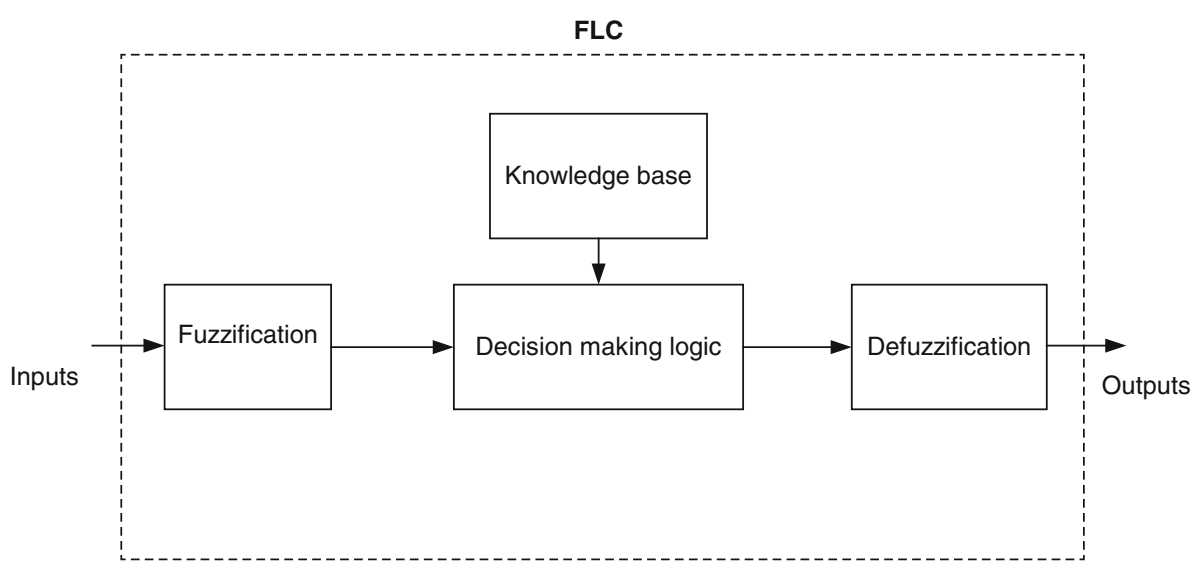




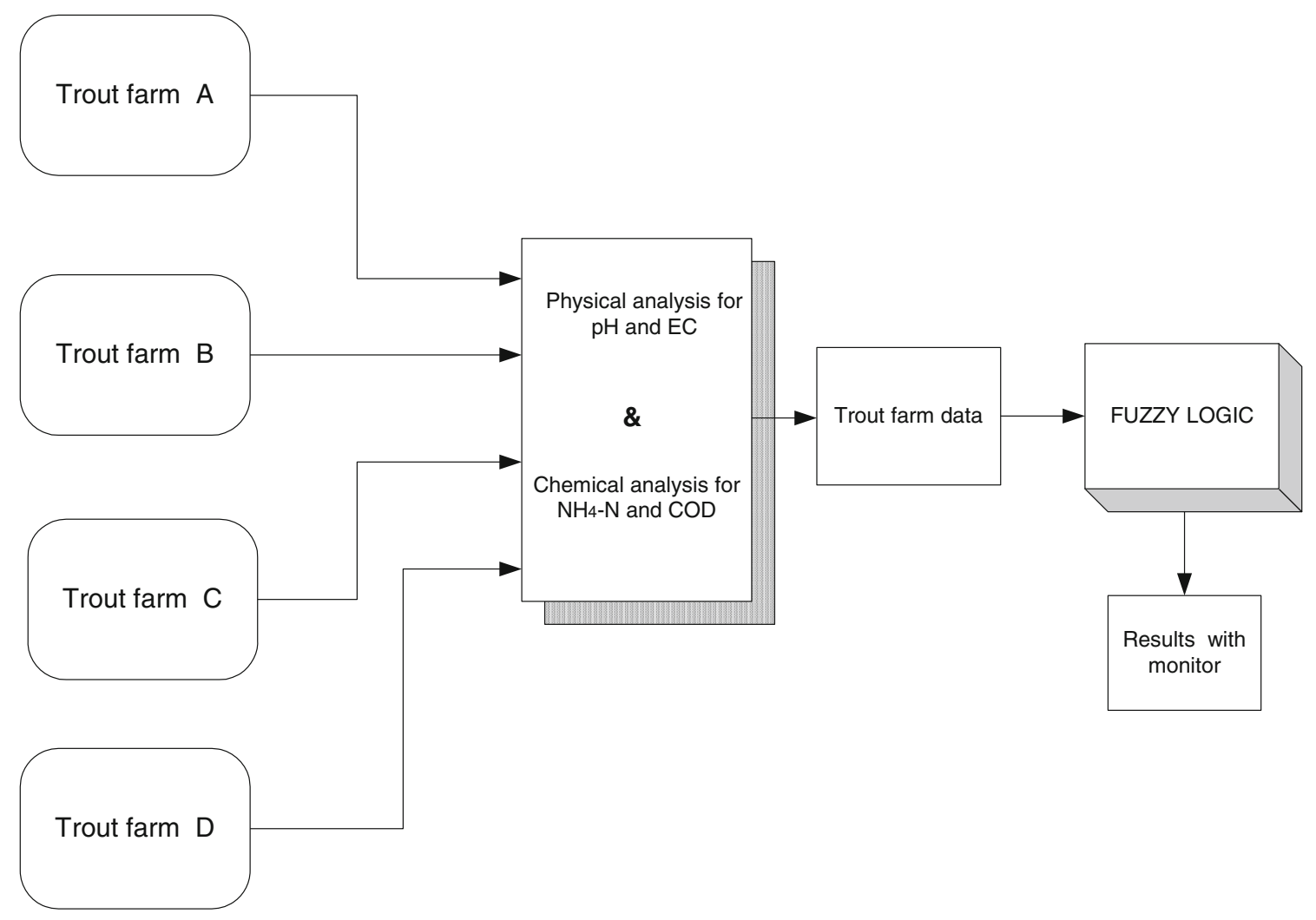

Fig. 3 Structure of the study

\section{Result and discussion}

Water samples were taken from four trout farms at different times, and $\mathrm{pH}, \mathrm{COD}, \mathrm{NH}_{4}-\mathrm{N}$ and $\mathrm{EC}$ parameters in farm waters were investigated. The values were subject to chemical and physical analyses. The results are presented with "Investigation of COD change," "Investigation of $\mathrm{NH}_{4}-\mathrm{N}$ Change," "Investigation of EC change," "Investigation of $\mathrm{pH}$ change" sections.

Fuzzy logic method was used due to the multitude of the obtained data and to eliminate time and expert requirements in the evaluation. Parameter changes in pool are investigated by using input and output data with fuzzy logic, and the results are presented on the monitors. Matlab-GUI is used as a convenience to the user. When fuzzy logic runs, monitor opens; information on water quality can be read at any moment from the monitor. The results are given in "Evaluation of pool water quality" section.

Investigation of COD change

COD is an important parameter in determining the pollution degree of waste waters. Organic matters in waste waters are determined with this parameter as oxygen amount required for chemical oxidations. The water sources of pools in $\mathrm{A}, \mathrm{B}$ and $\mathrm{C}$ farms originate from mountain, while the water source of $\mathrm{D}$ farm comes from artesian. The change of COD parameter is directly related to mean precipitation amount, sampling time, the feeding practice and fish wastes. The mean precipitation values obtained from State Meteorological Service (SMS) are given in Table 3. COD fell below critical value in the pools of B-C-D farms in November when rainfall amount was low with $5.2 \mathrm{~kg} / \mathrm{m}^{3}$. The months when COD value in pool was under critical value are October-December for A farm, October-November-December and April for B farm, November and March for $\mathrm{C}$ farm and October-NovemberDecember-April for D farm. On the contrary, the high precipitation amount sometimes makes organic pollutants to be diluted, which could cause this value to be observed low. In times other these specified months, COD value became higher than critical value in general. In this case, fish wastes and sampling time corresponding to feeding time as well as decreasing precipitation amount and organic matters joining in pools could result in high level of COD. Organic matter quantity in water decreases on account of the increasing seasonal temperature and water temperature as well as accelerating microbial activities.

The difference in the COD levels of the inlet and the outlet waters in farm A was statistically insignificant 


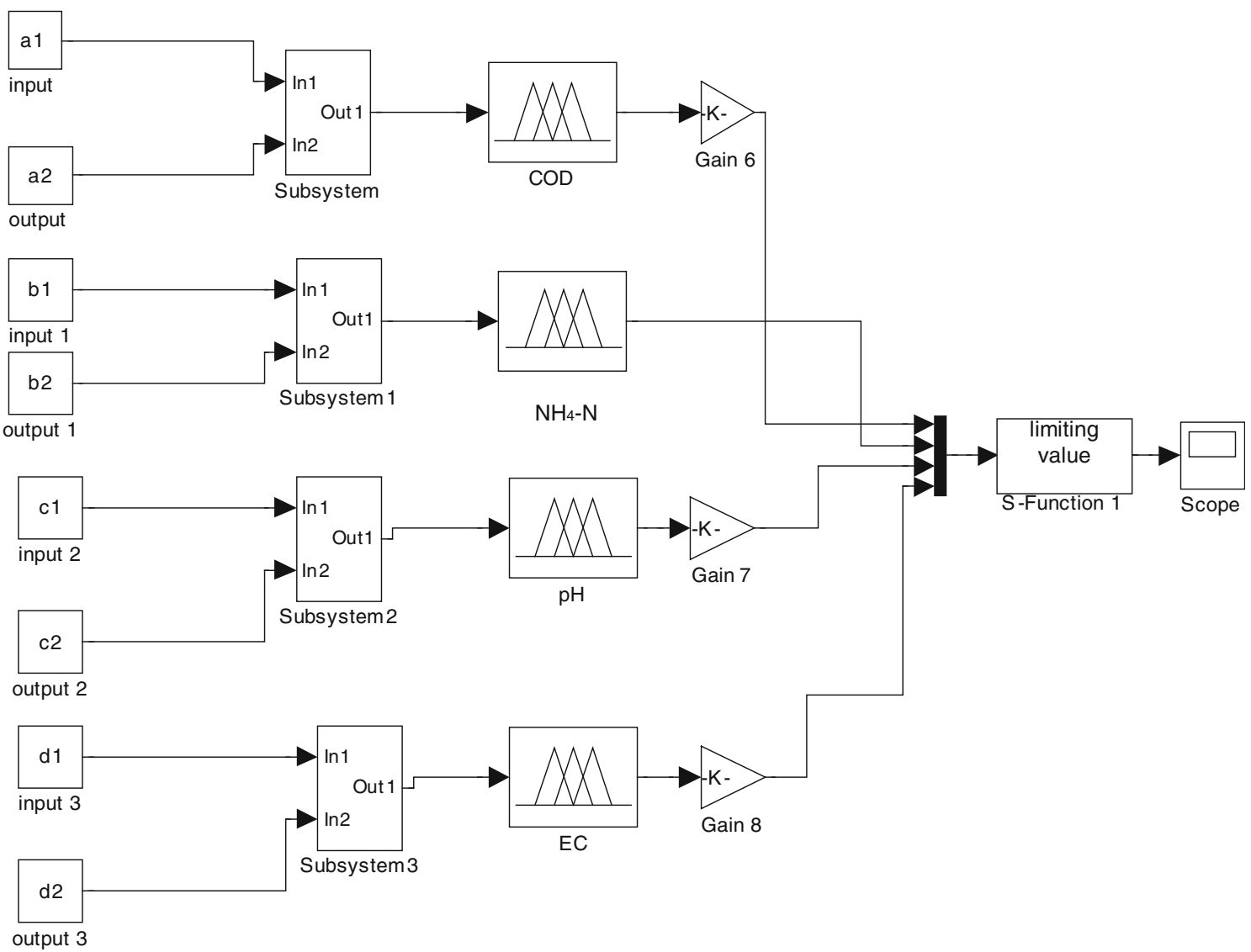

Fig. 4 Matlab-Simulink diagram for the system

Fig. 5 Structure of fuzzy logic

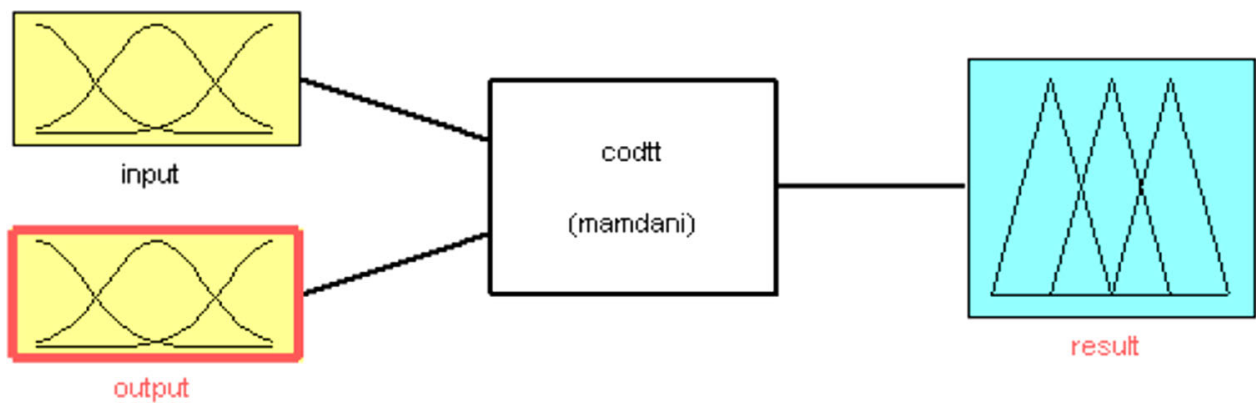

$(t=-0.202, d f=9, p=0.844, p>\alpha, \alpha=0.05)$. Similarly, the difference in the COD levels in the inlet and the outlet waters in farm B was also statistically insignificant $(t=0.536, d f=9, p=0.605 p>\alpha, \alpha=0.05)$. The difference in the COD levels in the inlet and the outlet waters in farm $\mathrm{C}$ and $\mathrm{D}$ was also statistically insignificant $(t=0.098, d f=9, p=0.923 p>\alpha, \alpha=0.05),(t=-$ 0.484, $d f=9, p=0.634 p>\alpha, \alpha=0.05)$.

\section{Investigation of $\mathrm{NH}_{4}-\mathrm{N}$ Change}

Ammonium ion is not considerably toxic to aquatic organisms. $\mathrm{NH}_{4}-\mathrm{N}$ exists in rather low quantity in clean waters with abundant oxygen. It is the waste product of aquatic creatures and reabsorbed by organisms. $\mathrm{NH}_{4}-\mathrm{N}$ can be directly taken by algae and high plants. Its quantity should be $1 \mathrm{mg} / \mathrm{L}$ or lower. Ammonium ion rarely exists in waters with abundant oxygen (Cirik and Cirik 1999).

Important part of waste products left in water in fish production consists of nitrogenous matters. Particularly, the nitrogenous matters in feeds and fish excretion could cause significant problems in water.

The mean level of $\mathrm{NH}_{4}-\mathrm{N}$ in $\mathrm{A}-\mathrm{B}-\mathrm{C}$ farms that use water of mountain origin was generally lower than the limits value of $1 \mathrm{mg} / \mathrm{L}$. However, input ammonium level is higher than output in $\mathrm{D}$ farm using underground water. 

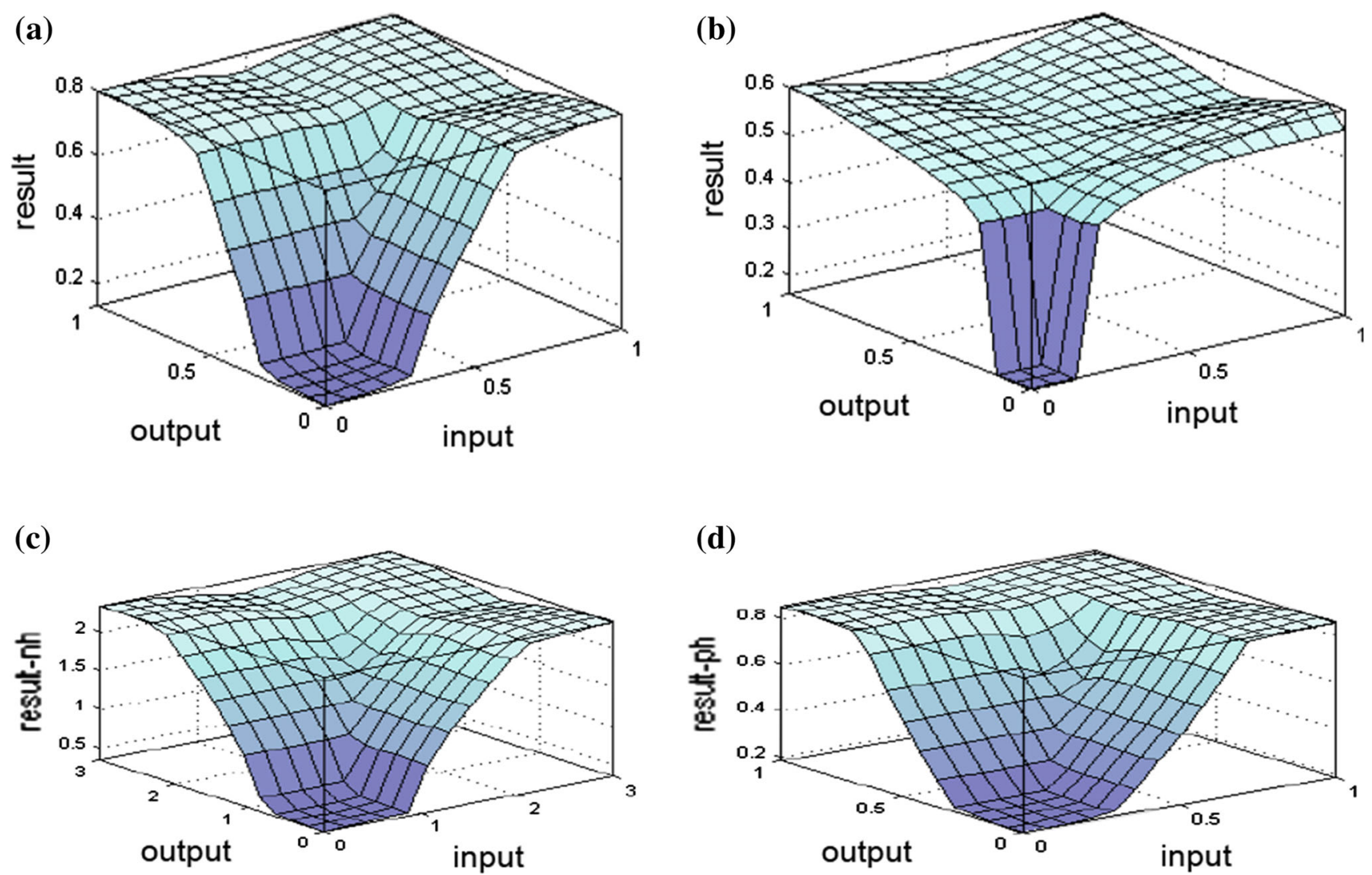

Fig. 6 Surfaces of the fuzzy logic for the parameters a COD b EC c $\mathrm{NH}_{4}-\mathrm{N} \mathrm{d} \mathrm{pH}$

(a)

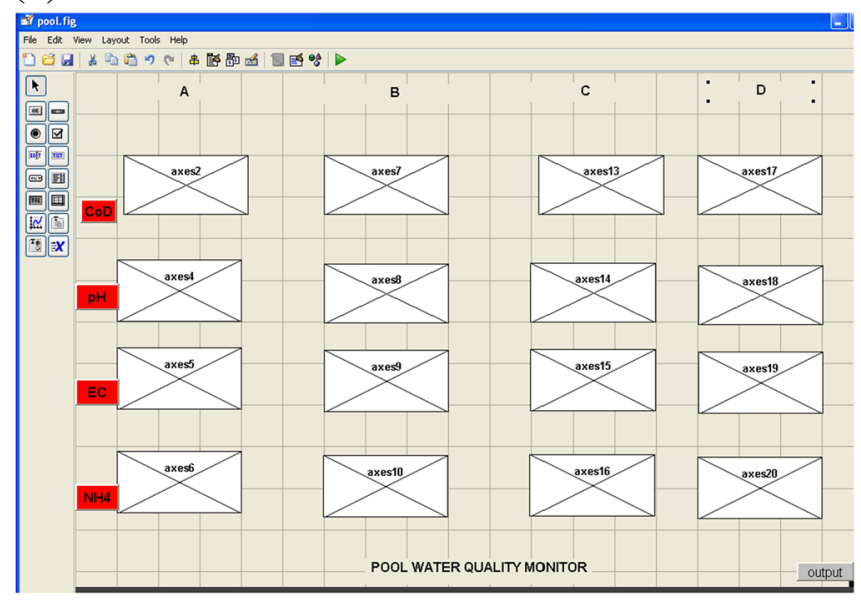

(b)

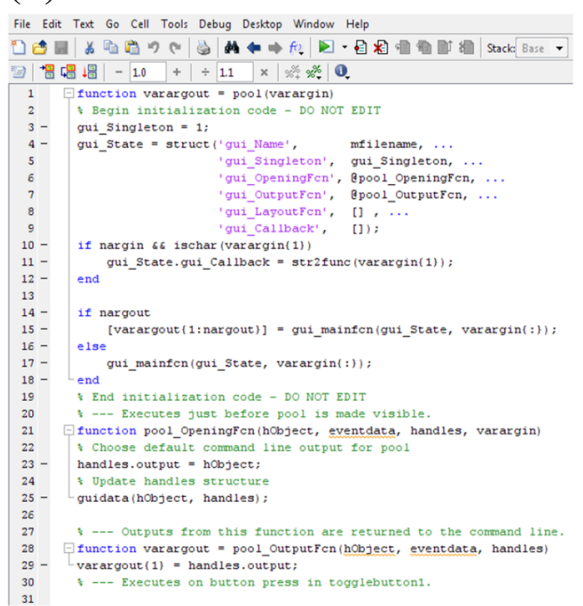

Fig. 7 Saving process results in two files; a pool.fig and $\mathbf{b}$ pool.m

Ammonium level increases in anaerobic underground environment. However, nitrification speed accelerates with the aeration of water taken in pool and thus nitrite and nitrate quantities increase. In the year round measurements, the mean ammonium level remained below $1 \mathrm{mg} / \mathrm{L}$ in $\mathrm{B}-$ $\mathrm{C}-\mathrm{D}$ farms. However, it exceeded or stayed very close to
$1 \mathrm{mg} / \mathrm{L}$ in A farm during summer months in general. This is considered to be caused by nitrogenous matters released through fish excretion and fish reproduction.

The difference in the $\mathrm{NH}_{4}-\mathrm{N}$ concentrations in the inlet and the outlet waters in farm A was statistically insignificant $(t=-0.076, d f=9, p=0.941, p>\alpha, \alpha=0.05)$. 
Similarly, the difference in the $\mathrm{NH}_{4}-\mathrm{N}$ concentrations in the inlet and the outlet waters in farm B was also statistically insignificant $(t=-2.121, d f=9, p=0.063 p>\alpha$, $\alpha=0.05)$. The difference in the $\mathrm{NH}_{4}-\mathrm{N}$ concentrations in the inlet waters of farm A and farm B was also statistically insignificant $\quad(t=0.144 d f=18, \quad p=0.887 \quad p>\alpha$, $\alpha=0.05$ ) since both farms use the same water resource as their inlet water. The investigation of the outlet waters did not reveal a statistically significant difference either $(t=-$ $0.741, d f=18, p=0.469, p>\alpha, \alpha=0.05)$. The difference in the $\mathrm{NH}_{4}-\mathrm{N}$ levels in the inlet and the outlet waters in farm $\mathrm{C}$ and D also statistically insignificant $(t=0.653$, $d f=9, p=0.522 p>\alpha, \alpha=0.05),(t=-0.017, d f=9$, $p=0.986 p>\alpha, \alpha=0.05)$.

\section{Investigation of EC change}

$\mathrm{EC}$ is an indicator for the quantity of total solved matter in water. Conductivity changes by geological structure and precipitation amount; however, it is not affected by nutrient salts in water (Temponeras et al. 2000). The EC values of waters suitable for fish production generally change between 150 and $170 \mu \mathrm{S} / \mathrm{cm}$ (Bremond and Vuichard 1973). It is reported that snow waters generally reduce the electricity conductivity (Savaş and Cengiz 1994). EC is cited among the values $(150-500 \mu \mathrm{S} / \mathrm{cm})$ stated in the protocol about fishery product standards and protection of superficial water sources against pollution (Uslu and Türkman 1987). Electrical conductivity was generally higher than $500 \mu \mathrm{S} / \mathrm{cm}$ in D farm. The source of pool water in D farm is artesian. Electricity conductivity is considered to increase as the water contains high amounts of ion.

It is known that the metabolic wastes increase due to vital activities of fishes, and electricity conductivity increases due to feeding activities. Therefore, EC possibly increases in periods when fish production increases, and decreases vice versa.

The difference in the EC of the inlet and the outlet waters in farm A-B-C-D was statistically insignificant $(t=-0.093, \quad d f=9, \quad p=0.927, \quad p>\alpha, \quad \alpha=0.05)$, $(t=0.178, d f=9, p=0.860, p>\alpha, \alpha=0.05),(t=560$, $d f=9, p=0.583, p>\alpha, \alpha=0.05)$ and $(t=-0.814$, $d f=9, p=0.426, p>\alpha, \alpha=0.05)$, respectively.

\section{Investigation of $\mathrm{pH}$ change}

$\mathrm{pH}$, which is an indicator of water acidity, is also one of the important factors that affect organism life. It changes between 6 and 9 in rivers not polluted in anyway. Most fish species show a good development in waters with $\mathrm{pH}$ between 6.5 and 8.5 (Arrignon 1976; Dauba 1981), while waters with $\mathrm{pH}$ higher than 10.8 and lower than 5.0 could be deadly for cyprinidae (especially for carps) (Svobodá et al. 2001). Alkaline waters are more suitable for trout production in general. Trout fishes can live in waters with 4.5-10 pH; however, the waters with 7.5-8.0 $\mathrm{pH}$ are best for them (Özdemir 1994).

When $\mathrm{pH}$ of fish production water decreases below 5.5 in trout farms, normal ovulation process is disrupted, and with $\mathrm{pH}$ under 4.5 , species would face depletion and production activities are completely destroyed. Acidity property of snow fall increases and if it falls on water, it could abruptly increase the water acidity. This could cause acid shock. Then, acidity kills living organisms. In addition, birds and mammals fed on these organisms are also adversely affected. Increasing acidity of waters disrupts the internal balance of fishes, and it results in calcium dissolution from osseous structure. It could cause important malformation like lordosis in fishes (Özdemir 1994).

The mean $\mathrm{pH}$ values of input and output samples taken from trout farms during 270 days of study period are 8.40 and 8.29 in A farm, 8.21 and 8.23 in B farm, 8.25 and 8.21 in C farm and lastly 7.43 and 7.54 in D farm, respectively. As there is no significant decrease in $\mathrm{pH}$ levels of input and output waters in trout farms according to experiment results, these values were observed to fall within the limits that would be suitable for trout cultivation.

The difference in the $\mathrm{pH}$ of the inlet and the outlet waters in farm A was statistically significant $(t=2.333$, $d f=9, p=0.045, p<\alpha, \alpha=0.05)$. However, the difference in the $\mathrm{pH}$ of the inlet and the outlet waters in farm B was statistically insignificant $(t=-0.338, d f=9$, $p=0.743 p>\alpha, \alpha=0.05)$. The difference in the $\mathrm{pH}$ of the inlet waters of farm A and farm B was observed to be statistically significant $(t=3.067, d f=18, \quad p=0.009$ $p<\alpha, \alpha=0.05)$ since both farms use the same water resource as their inlet water. The investigation of the outlet waters did not reveal a statistically significant difference $(t=1.711, d f=18, p=0.104, p>\alpha, \alpha=0.05)$. The difference in the $\mathrm{pH}$ levels in the inlet and the outlet waters in farm $\mathrm{C}$ and D also statistically insignificant $(t=0.321$, $d f=9, p=0.752 p>\alpha, \alpha=0.05),(t=-0.683, d f=9$, $p=0.503, p>\alpha, \alpha=0.05)$.

In "Investigation of COD change" and "Investigation of $\mathrm{pH}$ change" sections, the monthly graphical results of mean input and output values of COD, $\mathrm{pH}, \mathrm{NH}_{4}-\mathrm{N}$ and $\mathrm{EC}$ are given for each pool. These data were obtained by expert analysis.

For the obtained Fig. 8(a-d), a total of 21 samples were taken from pools at different times for 270 days of study period. The initial 3 values in figures represent the results in August, 4-6 values the results in September, 7-10 values the results in October, 11-12 values the results in November, 13-14 values the results in December, 15-16 values the results in January, while no-17 value indicates the results in February, 18-19 values the results in March 


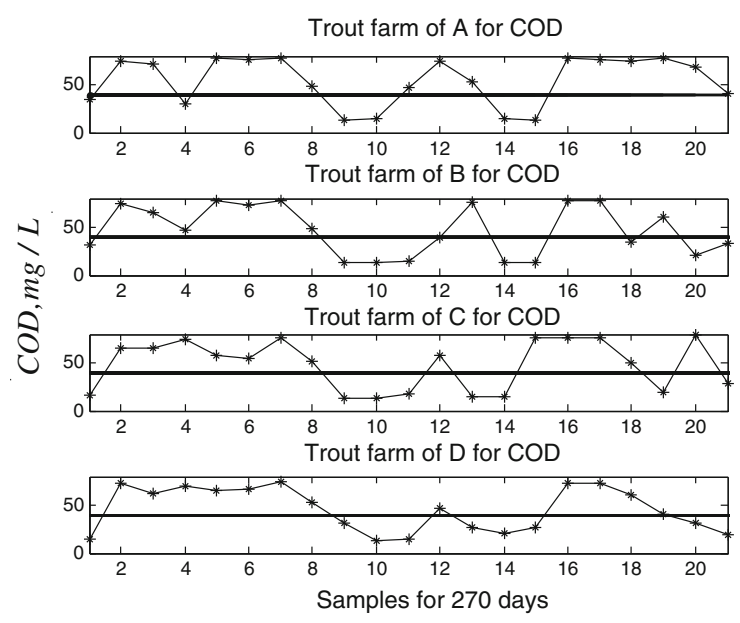

(a) COD changes in farms

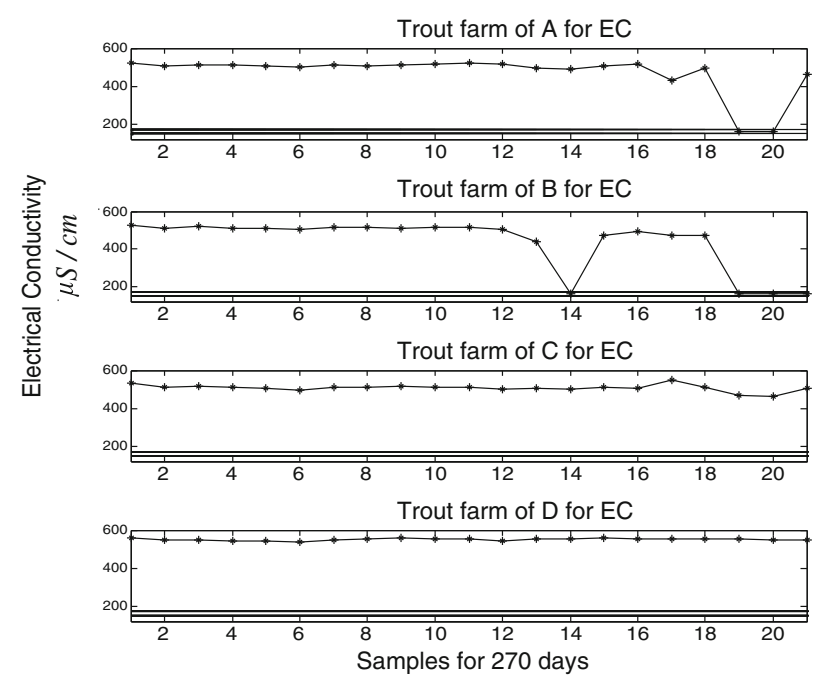

(c) EC changes in farms

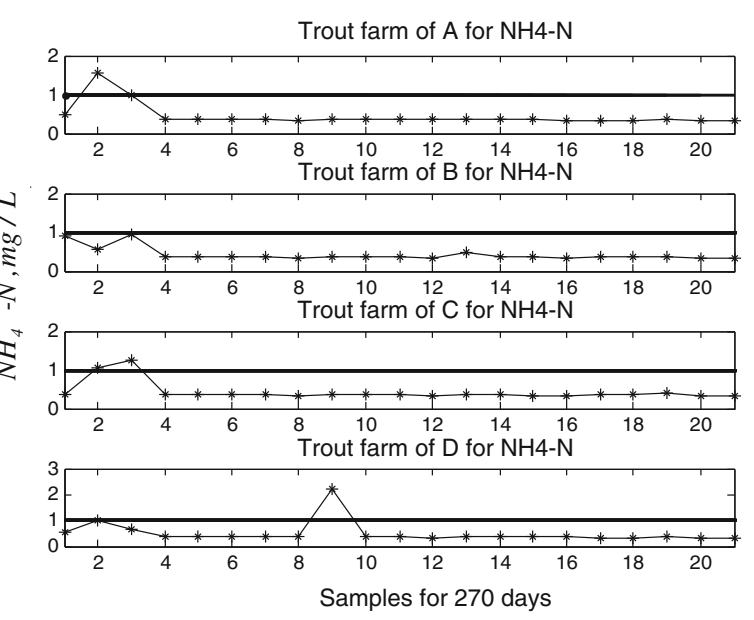

(b) $\mathrm{NH}_{4}-\mathrm{N}$ changes in farms

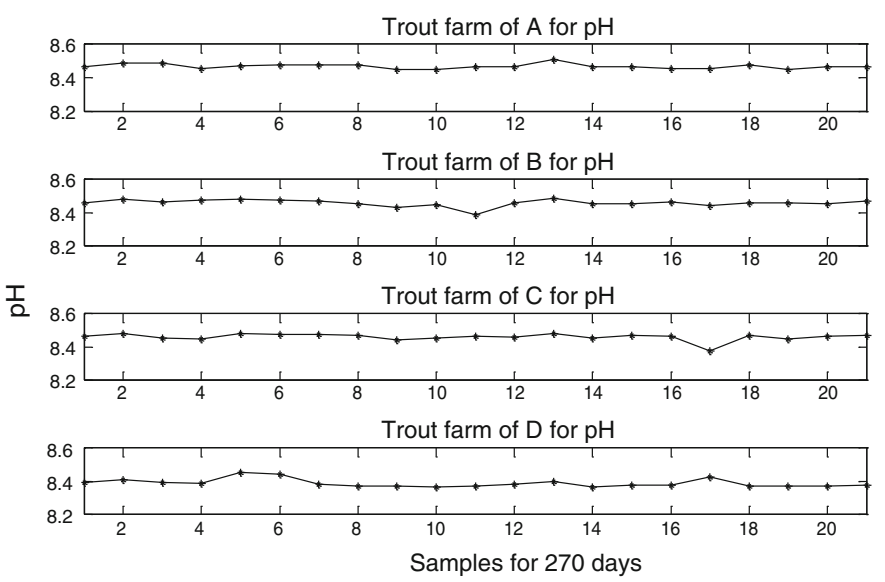

(d) $\mathrm{pH}$ changes in farms

Fig. 8 Parameters change in farms $(\mathbf{a}, \mathbf{b}, \mathbf{c}, \mathbf{d})$ a COD changes in farms, $\mathbf{b} \mathrm{NH}_{4}-\mathrm{N}$ changes in farms, $\mathbf{c} \mathrm{EC}$ changes in farms, $\mathbf{d} \mathrm{pH}$ changes in farms

and lastly the 20-21 values the results in April. Thus, the data of samples could be instantaneously examined instead of mean values, and necessary precautions can be taken in case of over limiting value for trout production as shown in Table 1.

Figure 8 a shows the COD parameter change for $\mathrm{A} / \mathrm{B} / \mathrm{C} /$ $\mathrm{D}$ pools. As can be seen, COD parameter is lower than the critical value at the end of October and December and at the onset of January for A pool. COD value is high in other months. Critical value is demonstrated with a bold black line. On the other hand, COD is under limit value at the end of October and December, at the onset of November and January, and in April in B pool. It is under limit value at the end of October and December and at the onset of November and January and at the end of March in $\mathrm{C}$ pool.
Lastly, it is under limit value at the end of October, at the onset of November, December and January, and in April in D pool.

In Fig. 8b, $\mathrm{NH}_{4}-\mathrm{N}$ parameter is examined for each pool. $\mathrm{NH}_{4}-\mathrm{N}$ should be lower than $1 \mathrm{mg} / \mathrm{L}$. The bold straight line in figure indicates the value $1 \mathrm{mg} / \mathrm{L}$. An increase was observed in pool $\mathrm{A}$ at the onset of August, while it remained under $1 \mathrm{mg} / \mathrm{L}$ in other months. There was not increasing trend in pool B for 270 days of study period. There was a slight increase in pool $\mathrm{C}$ at the onset of August, while it remained under $1 \mathrm{mg} / \mathrm{L}$ in other months. On the other hand, there was an increase in pool D in the middle of October, but it followed the desired level afterward.

Figure $8 \mathrm{c}$ represents the EC changes for $\mathrm{A} / \mathrm{B} / \mathrm{C} / \mathrm{D}$ pools. The acceptable limits of EC are indicated with a straight 
line. As can be seen, EC is between 150 and 170 at the end of March and the beginning of April in pool A, while it is higher in other months. EC is in acceptable level at the end of March and April in pool B. EC was not within acceptable levels in $\mathrm{C}$ and $\mathrm{D}$ pool along the year.

Figure $8 \mathrm{~d}$ shows the $\mathrm{pH}$ changes in $\mathrm{A} / \mathrm{B} / \mathrm{C} / \mathrm{D}$ pools. A total of 21 samples were collected for 270 days. As a result

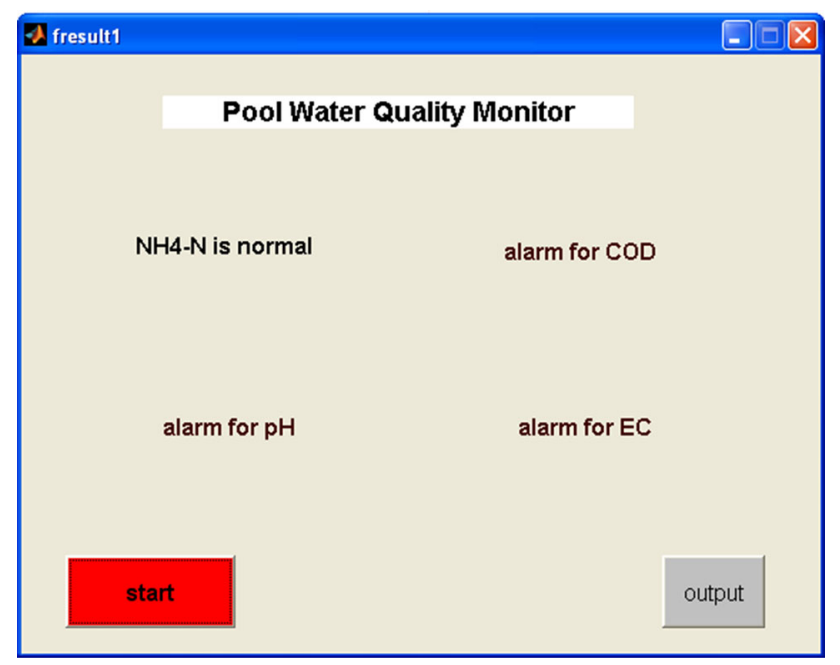

Fig. 9 Results of pool water quality on the monitor of the samples obtained from all pools, the lowest $\mathrm{pH}$ belongs to pool $\mathrm{D}$.

Evaluation of pool water quality

The evaluation of expert is transferred to programming and fuzzy logic is used. A program was developed even for those people with inadequate knowledge about the matter to interpret the situation by simple graphics. Data could be evaluated as either instantaneous or massive data sets, and a conclusion is reached about the quality of water with the monitor.

When the pool water quality is examined with fuzzy logic, two monitors are used. The first one shown in Fig. 9 showed the status of the parameters as text along with the "start" and "output" buttons. This monitor will supply more facilities for the user.

The second pool water quality monitor showed the results as graphics as shown in Fig. 10. The monitor showed the parameter changes for the four different pools during the year. When a change of the displayed parameters was desired, the corresponding button was pressed. Straight lines indicate the limit values for each parameter displayed. Comments could be recorded easily according to the limit values for the parameters. When the limit values were exceeded, water quality was judged as poor.

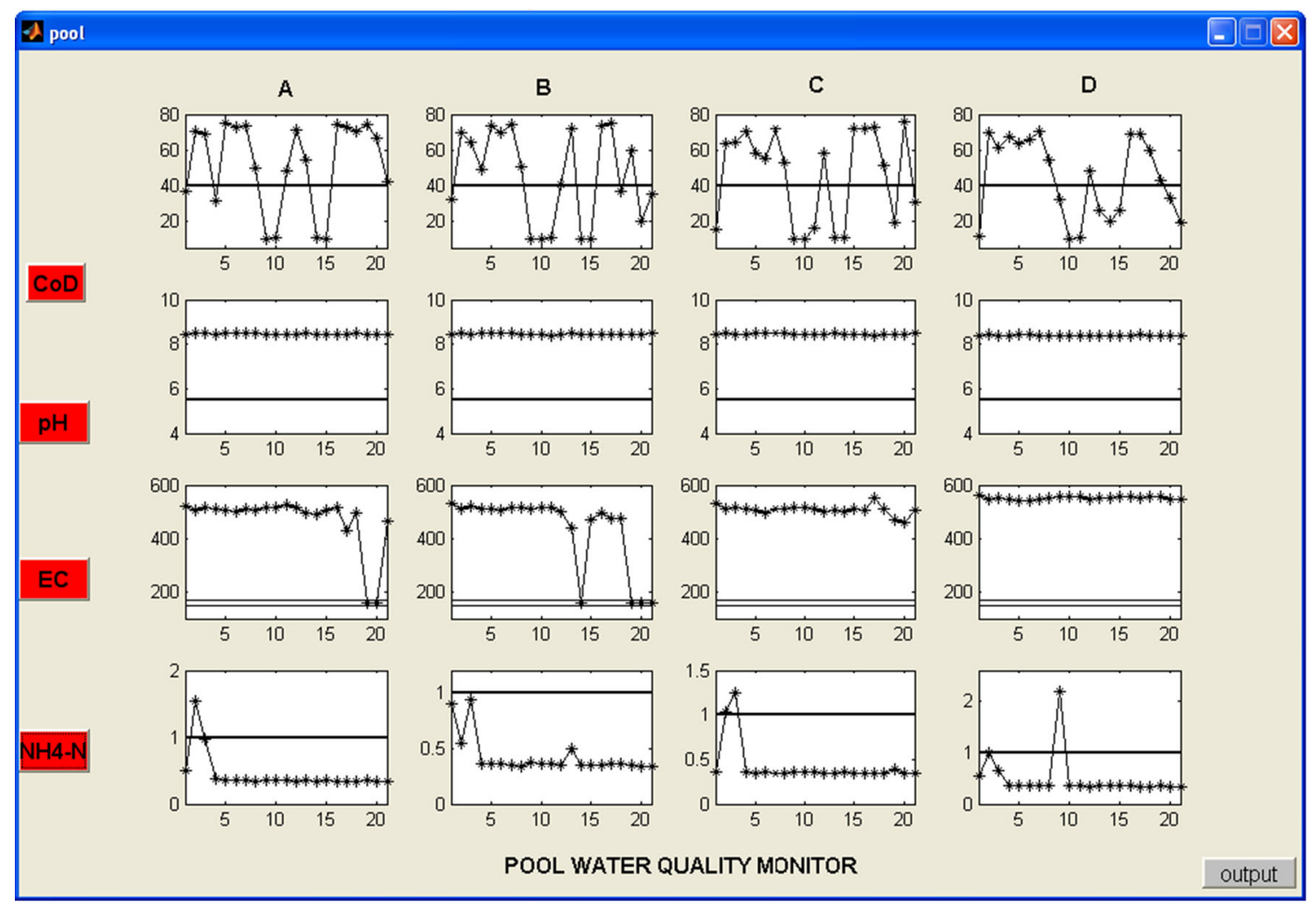

Fig. 10 Graphical results of pool water quality displayed on the second monitor 
As can be seen from the results, a module has been developed to inform user without any knowledge when limits are exceeded in trout production ponds.

\section{Conclusion}

This study is designed to bridge the gap in environmental monitoring and evaluate the water quality of trout farm. Water samples were collected from four trout farms at different times, and the $\mathrm{pH}, \mathrm{COD}, \mathrm{NH}_{4}-\mathrm{N}$ and $\mathrm{EC}$ parameters in farm waters were investigated. The values were obtained by chemical and physical analyses. Pollution parameter changes of inlet and outlet water of the pools are examined statistically with SPSS (PASW 18). As a result of the analyses on water quality of trout farms, a large data set was formed. The evaluation of this data set and reaching a conclusion requires both expert and time. Fuzzy logic was used to eliminate these requirements. A program was developed by Matlab/Simulink. GUI been used to make the results more clear about the water quality. When fuzzy logic starts to run, GUI window is opened, and the status of the parameters could be monitored easily. Accordingly, the program was designed to explain the situation to even those people with inadequate knowledge about the matter. A conclusion about water quality can be shortly reached by examining the data in either instantaneous or massive groups. In case of a exceeding limiting condition, fish producer is informed and financial damages can be minimized. In this way, this program is concluded to be effective in observing water quality of pool in both small-sized and large-sized trout farms.

Acknowledgments The data acquired with farms were obtained from scientific research project with project number of 2011.09.04.418 that was managed by Dr. Arda Yalcuk. We would like to thank project group.

\section{References}

Anonymous (2005) Standard methods for the examination of waste and wastewater, 20th edn. APHA, AWWA, Washington

Arrignon J (1976) Amenagement ecologique et piscicole des eaux douces. Bordas, Paris 322

Aydin F (2008) Trout-breeding, biology, cultivation techniques-1, Ankara University, Faculty of Agriculture. http://www.gidacilar. net/tatli-su-baliklari/alabalik-yetistirme-teknikleri-111.html

Bergheim A, Brinker A (2003) Effluent treatment for flow through systems and European Environmental Regulations. Aquac Eng 27:61-77

Boyd CE (2003) Guidelines for aquaculture effluent management at farm-level. Aquaculture 226:101-112

Bremond R, Vuichard R (1973) Parameters de la qualite des eaux: Ministere de la Protection de la Nature et de Environnement, Documentation, Française, Paris, $179 \mathrm{p}$
Canavese D, Ortega NRS, Queirós M (2014) The assessment of local sustainability using fuzzy logic: an expert opinion system to evaluate environmental sanitation in the Algarve region Portugal. Ecol Indic 36:711-718

Carbajal-Hernández JJ, Sánchez-Fernández LP, Carrasco-Ochoa JA, Martínez-Trinidad JF (2012) Immediate water quality assessment in shrimp culture using fuzzy inference systems. Expert Syst Appl 39:10571-10582

Cirik S, Cirik Ş (1999) Limnology, 3. Print, Ege University, Faculty of Fisheries, Ege University Press publications no: 21, İzmir

Dauba F (1981) Etude comperative de la fauna des poissons dans les ecosystemes de deux reservoirs: Luzech (Lut) et Chastang (Dordogone): These de troisieme cycle L'Institut National Polytechnique deToulouse, $179 \mathrm{p}$

Elmas Ç (2003) Fuzzy Logic Controllers. Seçkin publishing, Turkey [In Turkish]

Emami SMR (2010) Fuzzy logic applications in chemical processes. J Math Comput Sci 1(4):339-348

Forenshell G (2001) Setting basin design. Western Regional Aquaculture Center, WRAC-106. USA, 6 pp

Garrido R, Adroer M, Poch M (1997) Wastewater neutralization control based in fuzzy logic: simulation results. Ind Eng Chem Res 36:1665-1674

Henderson AR, Davies IM (2000) Review of aquaculture, its regulation and monitoring in Scotland. J Appl Ichthyol 16:200-208

Islam N, Sadiq R, Rodriguez MJ, Francisque A (2013) Evaluation of source water protection strategies: a fuzzy-based model. J Environ Manag 121:191-201

Koçer MAT, Sevgili H (2014) Parameters selection for water quality index in the assessment of the environmental impacts of landbased trout farms. Ecol Indic 36:672-681

Lindhorst-Emme W (1990) Forellenzucht. Bedarf Produktion, Werbung, Absatz Verlag Paul Parey. Hamburg und Berlin, pp 157

López M, Martínez S, Gómez JM, Herms A, Tort L, Bausells J, Errachid A (2009) Wireless monitoring of the pH, NH4-N and temperature in a fish farm. Procedia Chem 1:445-448

MathWorks. http://www.mathworks.com/help/toolbox/simulink/sfg/ f6-151.html. Accessed May 2012

Midlen A, Redding TA (1998) Environmental management for aquaculture. Kluwer Academic Publishers, London, p 215

Miller D, Semmens K (2002) Waste Management in Aquaculture. West Virginia University Extension Service Publication No. AQ02-1, 8 pp. USA

Ocampo-Duque W, Osorio C, Piamba C, Schuhmacher M, Domingo JL (2013) Water quality analysis in rivers with non-parametric probability distributions and fuzzy inference systems: application to the Cauca River, Colombia. Environ Int 52:17-28

Özdemir N (1994) Sweet and salty waters of Trout Production Firat University issue 35. 219s Elazıg-TURKEY

Passino KM, Yurkovich S (1997) Fuzzy control. Addison Wesley

Pillay TVR (1992) Aquaculture and environment. Fishing News Boks, Oxford $185 \mathrm{p}$

Postalcioglu Ozgen S (2009) Graphical user interface aided online fault diagnosis of electric motor-dc motor case study. Advances in electrical and computer engineering 9, pp 12-17. http://dx.doi. org/10.4316/AECE.2009.03003

Pulatsu S, Rad F, Köksal G, Aydın F, Benli ACK (2004) The impact of rainbow trout farm effluents on water quality of karasu stream. Turk J Fish Aquat Sci 4:9-15

Read PA, Fernandes TF, Miller KL (2001) The derivation of scientific guidelines for best environmental practice for the monitoring and regulation of marine aquaculture in Europe. J Appl Ichthyol 17:146-152

Savaş S, Cengiz M (1994) Köprüçay River with Lake Eğirdir, pouring out a research on the studies of water quality change. Ege Univ Aquac Mag 11:42-44 
Schulz C, Gelbrecht J, Rennert B (2003) Treatment of rainbow trout farm effluents in constructed wetland with emergent plants and subsurface horizontal waterflow. Aquaculture 217:207-221

Stephens M (2007) Creating GUI's in Matlab. http://www.maths. nuigalway.ie/ niall/workshop/guide_to_guide.pdf. Accessed 2012

Svoboda M (2001) Stress in fishes (a review). Bull VURH Vodnany 4:169-191 [In Czech]

Temponeras M, Kristiansen J, Moustaka-Gouni M (2000) Seasonal variation in phytoplankton composition and physical-chemical features of the shallow lake doirani, Macedonia, Greece. Hydrobiologia 424:109-122

Tsutsumi H, Kikuchi T, Tanaka M, Higashi T, Imasaka K, Miyazaki M (1991) Benthic faunal succession in a cove organically polluted by fish farming. Marine Pollution Bulletin 23:233-238 Uslu O, Türkman A (1987) Water pollution and control, Republic of Turkey Prime Ministry, General Directorate of Publications, Educational Series Environment 1, Ankara, p 364 